\title{
A managerial perspective of dynamic capabilities in emerging markets: The case of the Russian steel industry*
}

\author{
Gregory Ludwig, Jon Pemberton**
}

The paper critiques current thinking in the area of dynamic capabilities, exploring and challenging previous research on Dynamic Capabilities (DC) utilizing an application and empirical research within the Russian steel industry. Multiple sources of evidence arising from an in-depth study over a period of three years are deployed including semi-structured interviews with senior managers, as well as internal management reports, and other documentary evidence. The research concludes that practitioners need not choose between either routine-building on the one hand, or radical renewal on the other, but must recognize that dynamisms typically derive from the establishment of respective internal processes, followed by rapid-decision making.

Der vorliegende Beitrag befasst sich kritisch mit dem momentanen Wissensstand auf dem Spezialgebiet der "Dynamic Capabilities" (DC). Dies geschieht durch eine praktische Anwendung von Strategietheorie, kombiniert mit einer intensiven Datenerhebung in der Stahlindustrie der Russischen Föderation. Über einen Zeitraum von drei Jahren wurden empirische Daten durch zahlreiche aufgezeichnete Gespräche mit Topmanagern gesammelt, desweiteren interne und vertrauliche Berichte und andere industriespezifische Dokumente anlaysiert. Der fundierte Fachartikel schlussfolgert dass die Entwicklung von Dynamic Capabilities, ein Prozess der von Topmanagern geleitet und durchgeführt werden sollte, hauptsächlich interner und firmenspezifischer Natur ist und vor allem auf gezielten Entscheidungs-und Denkprozessen beruht.

Key words: strategy; dynamic capabilities; the Russian Federation; steel industry

Manuscript received: 09.07.2010, accepted 28.04.2011 (1 revision)

** Gregory Ludwig, Dr., Senior Lecturer in Strategic Management, Newcastle Business School. Main research areas: Dynamic capabilities through industry-specific application, with particular interest in the complexities surrounding the actual capability building exercises.

Jon Pemberton, Dr., Reader and Senior Lecturer in Research Methodology in Management, Business School, Edinburgh Napier University. Main research areas: Knowledge management and communities of practice. Corresponding address: J.Pemberton@napier.ac.uk 


\section{Introduction}

An increasingly complex national and international commercial landscape, combined with rapidly-changing economic and competitive conditions, present significant difficulties for organizations and their senior managers. Inter alia, it is unclear whether such challenges are further exacerbated by a struggle with implementation or planning, or whether organizations are victims of factors outside their control or, in some cases, if they exhibit a lack of capability building skills.

Consensus dictates that capability building necessitates changes in the near and far environment informed, ideally, by appropriate future forecasts of potential business and economic activity (Ambrosini et al. 2009; Pandza/Thorpe 2009). Other phenomena, such as the disappearance or sudden emergence of industries, also conspire to add a level of complexity to the challenges of strategic decisionmaking. Further frustrations arise when practitioners attempt to cope with the continual yet asymmetric and unpredictable fluctuations of the value of their own organizations, characterized by increasingly hard-to-define industries. The difficulties experienced in the banking and property sectors over the last two years perhaps reinforce this point. Thus, an ability to "remain in the game" represents a complex challenge from a managerial perspective, with the power of the boardroom somewhat diminished when confronted with the task of capability building and competition, and the macro-environmental changes that have devastated a range of industries.

In an attempt to assess its potential and real value in dealing with the contemporary challenges outlined above, the emergence of the area of dynamic capabilities (DC), but viewed through a managerial lens, is examined in this paper. Indeed, the subject of dynamic capabilities has provided an additional avenue for further evaluation and understanding of critical decision-making processes and their impact on the strategic challenges faced by organizations (Helfat/Peteraf 2003; Teece 2007).

Notwithstanding the recent and relevant publications in this area (Teece 2007; Lee/Kelley 2008), understanding of specific processes within dynamic capability building exercises may at best be described as incomplete in comparison with other more mature and established approaches to strategy such as the resource-based view (RBV) of the firm, for example.

Ironically, academics appear to have embraced DC tools as the universal solution, resulting in a plethora of propositions and prescriptions, but with little practical evidence to support such perspectives (Schreyögg/Kliesch-Eberl 2007). Specifically, a common theme within the published DC research appears to suggest that in high-velocity environments, increasing the speed of capability re-configurations loosely guided by external monitoring activities is a panacea for success. 
In an attempt to explore this further and utilizing evidence arising from an indepth study conducted over a period of three years, this paper provides an overview of the research on dynamic capabilities (DC) and seeks to identify factors which may facilitate and enable competitive survival in the light of current and anticipated dynamics within a particular context, notably the Russian steel industry. In doing so, it permits an examination of existing knowledge relating to dynamic capabilities to be realized within this sectoral context, with the objective of adding new perspectives to this important area of strategy research based on practical evidence. Such a choice of sector is particularly pertinent as it has operated in an environment shaken by a recent consolidation wave on a global scale which has affected big players and local producers alike (Stewart 2007; HSBC 2008) and might be described as a condensed model industry characterized by ever-changing external dynamisms. The latter are characterized by a number of features including rising labour and raw material costs, changing customer demands towards high-quality steel, new external competition through overseas acquisitions, and also the aftermath of trade wars with other nations such as Ukraine and China (KMPG, 2009; Olearchyk 2010). Indeed, it is particularly timely and pertinent to examine an exciting and fast-moving industry within the emerging markets sector, especially as the latter is indicative of a shifting balance in the global positioning of world trade and business.

From a managerial perspective, senior managers may lack the skills, resources and experience to manage firms in those fundamentally dissimilar and more competitive settings (Filatotchev et al. 1996; Peng and Heath 1996), and rapid external changes also conspire to aggravate the decision-making processes, which could result in managers being forced to reshape strategies and adapt to somewhat destructive market-driven, rather than firm-specific factors (Spicer et al. 2000). Added complications also arise when managers in the steel industry have to deal with practical obstacles such as the discovery of new fields, and the use of new methods of extraction and processing of iron ore. In essence, physical capacity building and maintenance, new facilities installation and development and replication of new technologies add to already high levels of complexity.

The research presented in this paper focuses on the managerial viewpoint pertaining to perceptions and realities of dynamic capabilities building within this particular context. This is particularly important given the fact that discussion of the content (what are they?) or processes (how are they built?) of DC can lead to wide-ranging and conflicting recommendations when generalised across industries.

The paper commences with a review and critique of key aspects of the development of dynamic capabilities and their current position within strategy research, against a backdrop of developments that have taken place specifically 
within the Russian steel industry. Details of the research approach adopted are then furnished, with evidence arising from interviews with a number of senior Russian managers together with other relevant documentary evidence. The findings provide the basis of discussion and analysis of the various themes emerging from within the body of knowledge on dynamic capabilities, advancing the understanding of concepts and ideas permeating the current debates in DC within strategy research. Furthermore, the implications for managers within the particular sector are set out, culminating in the identification of facilitators and barriers for DC processes, as well as suggestions for further avenues of research within this topical and contemporary area of strategic management.

\section{Examining the dynamic capabilities landscape}

A number of definitions of dynamic capabilities exist. Yung-Ching and TsuiHsu (2006:215), for instance, encapsulate them succinctly as "a set of specific and identifiable processes, or a pool of [controllable] resources that firms can integrate, reconfigure, renew and transfer".

Teece et al. (1997:509), however, explain that the development of DC flows from a recognition that "strategic theory is replete with analyses of firm-level strategies for sustaining and safeguarding extant competitive advantage, but has performed less well with respect to assisting in the understanding of how and why certain firms build competitive advantage in regimes of rapid change". They offer an explanation for this dilemma which is centred on the notion of path dependence, by arguing that it determines both future choices and future "domains of competence" (Teece et al. 1997:515). In other words, such decisions represent "quasi-irreversible commitments", perhaps a central weakness of the resource-based view. If competitive advantage solely rests on imperfect imitability based on trajectories which chart the future pathway of competence development for the organisation, this may adversely affect the organisation's ability to renew capabilities in response to changing environments (Schreyögg/Kliesch-Eberl 2007). Accordingly, for strategic managers, any attempt to embark on dynamisation of organisational capabilities inevitably leads to a number of complex challenges and implications. Furthermore, if capabilities per se represent "superior ways of allocating resources", then the danger is that capability-rigidity drivers such as path dependency, structural inertia or specific commitments, as outlined above, may considerably inhibit such action, or even prevent its implementation as part of daily routines.

Another feature of the DC literature pertains to the renewal process (Helfat/Peteraf 2003; Pitelis/Verbeke 2007; Teece 2007). Renewal tends to occur only if its feasibility is apparent. Consequently dynamic capabilities building processes, as central managerial tasks, essentially represent efforts 
towards possession, readiness and maintenance of appropriate resource material. Indeed, since dynamic capabilities first emerged in strategy theory nearly two decades ago, much of the subsequent research has focussed on the renewal aspects in causal connection with high velocity environments (Dutta et al. 2005; e Cunha/da Cunha 2006; Schreyögg/Kliesch-Eberl 2007). In one respect, as dynamisms are one of many elements rather than the core feature of today's business environment, future focus of the conceptual contribution of dynamic capabilities may need to move away from this particular locus of attention in order to provide more direct benefits for decision-makers - in practice, the dynamics derive mainly from case-to-case managerial evaluation. More specifically, it is subject to managers' explicit judgment of individuallygathered data, highlighting the day-to-day status of the objects of observation.

Despite the existence of this ever-changing fluid entity which acts as the basis for attempts at problem-solving, decision-making still remains within the managerial domain. The key parameters that guide the strategic process in this context consist of the following broad categories of elements further summarised below:

- Fluctuations in resource value,

- Fluctuations in impact of external factors,

- Determination of time frames which affect the resource maintenance activities and the speed of resource "depreciation".

The importance of these elements derives from their role as the broad categories of challenges faced by senior managers on a daily basis. The boardroom's task is to understand them and their constant evolution, in order to guide and inform their decision making.

Managerial freedom to move away from established capability building patterns, however, is quite restricted in certain industries and therefore does not represent a matter of strategic choice as indicated within the existing body of literature (Dosi et al. 2000; Zollo/Winter 2002; Danneels 2002; Miller et al. 2002). The main threat to flexibility essentially derives from feasibility constraints that strategic decision-makers of organizations typically encounter. As a result, the most plausible hazards are likely to be rooted in powerful path dependencies and frantic response to external changes. This means that managers are restricted in their capability-building movements and yet urged by stakeholders to do so. On the other hand, stakeholder groups may only focus on external changes without seeing firm-specific path-dependencies and expect immediate reactions from executive directors. Hence, the role of path dependencies may occupy a central and perhaps detrimental role within the wider context of theoretical schisms, contradictions and limitations pervading the DC literature to date.

Consequently, characteristics of business reality in certain industries may dissolve and diminish the strategic power attributed to organisational 
capabilities in the first place, particularly in the wider context of the RBV. It is perhaps significant that the concept of capabilities presents certain idiosyncratic and endogenous problems for practitioners that should not be ignored. For example, Schreyögg and Kliesch-Eberl (2007:915) explain that "problemsolving activities are not called capabilities unless they have proved to be successful across various situations and organizations are able to reproduce them". Managerial abilities to identify, monitor and repeat relevant routines thus represent perhaps the major basic challenge associated with organisational capabilities, yet, on their own, routines may not complement the nature of dynamic capabilities which are characterized by even further increased complexities.

Ethiraj et al. (2005) propose that capabilities are context- or industry-specific, and that any research in this area requires conceptualised investigation. In fact, conceptual work on the notion of organisational capabilities has tended to outpace empirical research in the past due to the difficulties of implementing performance measures and to identify and define significant capabilities and their individual deployment (Eisenhardt/Martin 2000; Haas/Hansen 2005; Schroeder et al. 2002). Indeed, the fact that generalisations across industries result in high abstraction levels and therefore do not fulfil the criterion of managerial guidance and applicability as one of the underlying foundations of the DC purpose and evolution certainly supports this notion. In the light of this, a motivating element of this study is an emphasis on the need to conduct industry-specific studies of dynamic capabilities which may then result in a more universal body of knowledge in the future designed to bridge the potential gap between abstract theoretical knowledge on DC and the practical relevance for senior managers.

With regard to theory building, the contributions of Teece (2007), Lillis and Lane (2007), Pitelis and Verbeke (2007) and Augier and Teece (2007) focus on theoretical progression of the concept of dynamic capabilities and related subtopics. Recent publications by Wu and Wang (2007), Harreld et al. (2007), Green et al. (2008), Lee and Kelley (2008), and Oliver and Holzinger (2008), represent attempts to transfer these abstract notions to a variety of business situations. Despite such advances, it is important to note that any generalisations across industries may appear premature at this time, and thus selective focus on specific contexts may be a more realistic means of progressing the theoretical domain of DC. It is worth noting, however, that the whole debate highlights a relatively fundamental danger in strategy research and practice: the temptation to develop seemingly universal recipes for organisational success despite their limited relevance for narrowly-defined business areas. 


\section{The Russian steel industry context}

The notion of dynamic capabilities, and the issue of generalisability detailed above, calls for further discussion of the context under investigation prior to discussing the research conducted in this paper.

In particular, during the last decade, the steel sector in general (World Steel Association 2011), and the Russian industry in particular, has been characterized by a range of mergers and acquisitions (M\&A), and a drive for higher quality steel, as well as a number of contextual and transitional factors which require discussion.

Within the Russian context, political factors such as the influence of the former President Putin had a direct bearing on the strategic decision-making power of directors of 'strategic sector' companies, including those operating in the steel industry ${ }^{1}$. In essence, the President's actions divided oligarchs, traditionally well represented at the top level of Russian organizations since the 1990s, into two categories (best described as 'supporters' or 'dissenters'), depending on their personal loyalty to the ruling government. As a result, companies were either split up and placed under government control (as in the case of Yukos, for instance) or "controlled" privatisation took place.

For a number of steel players this meant a move from public ownership to the private sector, with little focus on external environments and rigid management paradigms, but with the appointment of new chairmen and management directors resulting in increased political influence on these organizations. The direct implication, and simultaneously perhaps major difference to Western steel organizations, was the fact that in real terms, despite Initial Public Offerings and privatisation efforts, the majority of shares remained in the hands of single individuals, typically the director and/or $\mathrm{CEO}^{2}$.

\footnotetext{
1 The bill on strategic sector companies was at the stage of development in the year 2005 and it was not until 2008 that it passed all major readings in the Russian parliament. Because the rules at the time simply did not exist, the precedence of practice prevailed, i.e. President Putin determined what was acceptable/unacceptable conduct by actions of promotions (as in the case of the steel industry) or in reprimand of political, economic, and in most extreme cases physical nature (former Yukos CEO and majority shareholder Khodorkovsky; former Aeroflot and Sibneft shareholder Berezovasky; former MOST media CEO and shareholder Gusinksy, for instance.)

2 Unique to the Russian context is that the individual who maintained the position of power under the former President's rule did so at the expense of surrendering their decision making powers (integrity comes with political sanctioning while retention of wealth requires surrendering freedom of expression). In total contrast not surprisingly, this power map did not change with the election of a new Russian president who is very much perceived as a subordinate of (for now) Prime Minister Putin. to the earlier years of the Russian transition it has become unconceivable for an oligarch to float his shares in a strategic sector company on a public stock exchange without the green light from the Russian administrative elite. The highly hierarchical nature of the decision making process with the former President at the helm can be explained in these terms in the Russian context. Interestingly, and perhaps not surprisingly, this power map did not change
} 
To some extent, significant international expansion of Russian steel players through M\&A diminishes the wider importance of the issue for respective organizations and demonstrates that macro-environmental factors are often connected and interlinked. In this particular case, political factors have changed legal parameters. On the other hand, its specific history and economic transition from State Planning Committee-controlled operations in the 1980s to a market economy in the 1990s back to more indirect state control in the 2000s certainly continues to affect the steel industry. Hence, the Russian steel sector context shows that any industry analysis is dependent on certain degrees of anticipation of macro-environmental trends and, from purely external view, the industry is essentially an oligopolistic structure characterized by a few major players that dominate the entire micro environment.

In reality, four major players are spread over the geographical area of the Russian Federation, with little or no overlaps and almost a complete absence of competition within national borders. These are Novolipetskiy (NLMK), Severstal, Magnitogorsky Kombinat and Evraz. Further analysis shows that the Russian steel industry is divided into four distinct regions each dominated by one organisation respectively, which also has a bearing on any discussion of this sector and geographical region.

In conclusion, the need for dynamic capability building for Russian steel managers derives from a number of sources including geographical 'protectionism' (i.e. manipulated competition by the four key steel manufacturers), arrival of new competition caused by M\&A activities, and demand for high quality steel. The loss of strategic power due to formerly unknown external threats therefore provides an impetus for investigation of the issue of DC building within this unique context.

\section{Research approach}

The ensuing research evidence presented, and the arguments espoused in this paper, arise from the findings of a doctoral study conducted over the period 2006-8, informed by the current debates and critical discussion by key authors in the field, as outlined above. In view of the acknowledgement that DC highlight a high degree of complexity in the pursuit of capability building processes, it is clear that generalisation across firms and industries is unrealistic until further industry-specific studies on dynamic capabilities are published, critically reviewed and validated. This is reflected in the chosen research strategy described here, which centres on a single case study design, examining the nature of dynamic capability building in the Russian steel industry through the eyes of senior managers, and combining documentary evidence from archival records and management reports, with interviews of managers'

with the election of a new Russian president who is very much perceived as a subordinate of (for now) Prime Minister Putin. 
perceptions and experiences of an industry operating in a state of flux and uncertainty. The case study refers to a conglomerate within the Russian steel industry, with subsidiaries in Europe and America, and whose identity, for reasons of confidentiality, is not revealed. More specifically, a total number of 100 potential interviewees were originally contacted in 2006 via key informants and business partners of the conglomerate, followed by telephone calls, personal conversations and meetings, in order to realise the eventual face-to-face digitally-recorded sessions. Consequently, thirteen managers holding senior strategic planning roles within the case organisation agreed to partake in the study and were personally interviewed twice between January and December 2007. Interviews were carefully designed to highlight and examine the role of dynamic capability building for competitive survival within the industry under investigation and, furthermore, permit insights into the process-based nature of respective managerial actions. Appendix One gives a summary of the core areas discussed and explored during the interviews. Furthermore, over the period 2006-2008, documentary evidence in the form of internal confidential organisational strategy documents, provided by the interviewees, as well as additional senior managers from the case organisation, together with a range of management reports, allowed cross-referencing and corroboration of policies and context via this data triangulation, adding further relevance and construct validity to the findings (Irvine/Graffikin 2006).

The resulting interviews were analysed using a theme-based analysis of both pre-defined and emerging theoretical and practical issues related to dynamic capabilities building and its subdivisions. In this way, it allowed the establishment of a "closed circuit" from the research problem via the case study strategy and its unit of analysis, linking back to the overall research aims. Themes were retrieved through first-level coding resulting in summaries of segments of data and subsequent pattern coding, allowing reduction of large amounts of data into a smaller number of analytic units (Miles/Huberman 1994).

\section{Analysis}

The research undertaken reveals that dynamic capability building is generally a loose connection of very complex tasks in the Russian steel industry - both their industry compatibility and feasibility may not be automatically given and are case-specific. It transpires that a major pre-condition of the dynamic capability building exercise is the theoretical availability of decision-making speed, which in itself is subject to a number of critical factors. The evidence amassed also indicates that dynamic capabilities require continuous action and have their locus in daily managerial routines, rather than being linked with sophisticated managerial thought-processes characterized by extended development and implementation phases. Furthermore, continuous future forecasts constitute more of a pre-condition to dynamic capability building efforts than a direct element of the latter. Simultaneously, embarkation on these complex processes 
requires preliminary managerial awareness of their importance and detached from current financial evaluations. This is somewhat at variance to key performance indicators in certain instances. As a result, the managerial task of dynamic capability building is characterized by both specific action and deficiencies. More specifically, a consensus arising from the academic research conducted to date (Ambrosini et al. 2009; Teece et al. 1997), suggests that rapid resource modifications and the subsequent realisation of major disruptions to existing procedures for capability deployment may simply not be realistic. As regards this particular study, a number of reasons may contribute to this, which are also influenced by the nature of steel production, as well as technical and financial constraints. As one of the participating senior managers in the research study commented:

“......cost is definitely a big driver for any steel company. ..... and although you can produce some niche products, if you look at the bigger picture, pretty much any company is concerned about having the lowest costs of production. Big drivers of competitiveness for any company are raw material costs .... which probably represent $60 \%$ to $70 \%$ of the costs of any steel company". [Finance Director]

In the context of acquisition of raw materials, the interviewee elaborated further:

"..... where you buy your raw materials, how far you are located from the sources of raw materials...... do you have long term contracts? Do you acquire some sort of stake in your raw material supplier in order to be competitive?". [Finance Director]

Indeed, as in most large industries, competition is an integral feature and awareness of other competitors' activities in relation to resource and technology utilisation figures prominently, as illustrated by the same interviewee's comments:

“ there is operational improvement which you actually do in the process of production. Basically you are inventing new production processes which mean you can produce steel much cheaper than anybody else. You can be successful this way....... there are a lot of other mill technology processes in the steel industry, so if one of them proves to be successful, then we can probably become competitive by developing one of these technologies. Some companies invest heavily in new production processes which would eliminate hot furnaces as production sites; potentially companies will do it to be more competitive". [Finance Director]

Interestingly, as discussed earlier, there was an explicit acknowledgement that the Russian context did throw up some anomalies in terms of competition, as exemplified by one respondent, 
"Internally, we have three main competitors... but competition is not very strong because... Russia is spread geographically as a country and each of these competitors dominate their respective geographical region, for example”. [Director, Corporate University]

That said, companies appear to operate with a degree of complicity despite their regional advantages, if only to protect their position within the industry. As one manager noted,

“..., we are exchanging information with our competitors... and we try to ensure we get the prices we want... we don't want to see anyone in our market”. [Senior Manager Group Strategy and Controlling Department]

Indeed, there is some evidence of a united front as regards external competition too, with one interviewee commenting that

"... we have had rather strong relationships with two competitors from the 90s onwards...we know what they do and they know what we do... to be more competitive against foreign companies". [Senior Manager Strategic Planning Department]

In particular, the threat of Chinese competition is recognised, with an implicit acceptance that production of lower-grade steel is being reduced, and Russian companies concentrating on a move towards higher quality steel. As one interviewee noted,

"We still need low grade steel ......but I think Chinese metallurgical companies are pushing us as regards production of this low grade steel.......we can't compete with them in terms of costs".

However, whilst new technological developments have changed the balance of power to some degree, high-investment costs limit the pace of change and partially obscure elements of competition within the industry. A tacit recognition of this is supported by one manager, who argues that,

"Steel industry technologies have been used for many years practically unchanged. Equipment of steel producing plants is capital-intensive and in use for a long time.....new technology processes such as, iron making processes without coke....can't compete against blast furnaces”. [Director Business Planning]

Thus, in the steel industry, characteristics of the metallurgy production processes of physical nature may conspire to block dynamic capability building as a whole, mainly due to development time horizons and the inflexibility of respective processes. Thus, owing to its complexity and the theoretical procedures as detailed in earlier sections of this paper, dynamic capabilities may only be achievable in certain cases - accordingly, competitive survival in high velocity environments and simultaneous efforts of industry players to achieve this may be difficult to realise through traditional organisational structures. This 
particular finding supports, to some degree, the need to conduct industryspecific examination based on extensive studies which indicate potential barriers to the capability-building exercise. Previous studies on the issue appear to assume practical feasibility and supra-contextual validity in their presented theoretical frameworks (Helfat/Peteraf 2003; Schreyögg/Kliesch-Eberl 2007). Also, perhaps somewhat surprisingly, evidence reveals that, on balance, internal processes are of higher importance for DC-related application than a focus on external changes within the industrial sector and case organisation examined here. Monitoring itself appears to be directed at the actual internal resource material, financial scope for resource modification and constant identification of ongoing existing patterns for capability building in order to facilitate planning and execution of appropriate responses.

Arguably, the outcome of such pursuits needs to be entirely open and is not primarily led by current or past capability patterns - the notion and nature of risk is core to understanding established capability patterns within the concept of dynamic capabilities. According to the "traditional" DC theory, the managerial lens will usually determine whether observed signals arising from external factors are strong enough to be perceived as threats to the validity of ongoing capability building (Schreyögg/Kliesch-Eberl 2007; Green et al. 2008).

As one interviewee noted:

"Our success factor is management of resources. So we must adapt our resources to changes in the environment". [Senior Manager Strategic Planning Department]

In effect, the majority of dynamisms are ideally to be found within internal strategic practices and this particular finding represents a departure from the established perspective of DC, where the extant body of knowledge, exemplified by Eisenhardt and Martin (2000) and Ambrosini et al. (2009) for example, assumes risk minimisation via establishment of extensive monitoring activities of external changes in combination with capability optimisation through renewal efforts.

Although forecast activities are still considered as important from the managerial perspective, actions are often associated with current routines, and a range of perspectives was apparent, as exemplified by the comments of three interviewees:

“Just make money and don't think about the future. .....it's one approach. It's not very strategic... and you may lose.... you make money now and advantage your share- and stakeholders in terms of financial benefits....We don't see that the steel industry [is] on a decreasing line of the life cycle.......so we don't plan huge steps in terms of divestments or investments in other businesses. It's more important to make money today. What proportion? If we are trying to measure it, I think at least $80 \%$ are 
day to day pressures and only $20 \%$ is about anticipation of environmental changes". [Senior Manager Group Strategy and Controlling Department]

"If the management can rapidly make decisions and can predict what will happen... maybe the main aim of our department is to predict and to make forecasts of what will be tomorrow". [Senior Manager Strategic Planning Department]

"Strategic forecasting is very important for our company because it is possible to react more actively to external changes". [Director Strategic Planning]

In essence, although managers recognise the importance of future forecasting, activity is more likely to centre on reacting to internal constraints, but with recognition that developments and behaviours of competitors also govern that capabilities to perform and innovate accordingly. This is succinctly illustrated by one interviewee who observed:

"In general, if competition is weak, it's enough to have tangible resources. But by the time competition becomes stronger, our intangible capabilities and competencies become more important .... the importance of nonphysical resources will be critical ... companies should monitor changes". [Director Corporate University]

The managerial accounts contained in the research undertaken make it explicit that path dependencies potentially restrict the DC building exercise because established strategic routines for capability utilisation are the only available options as the impact of cost factors and industry characteristics prevails. Interviewees emphasised that, for example, rapid resource modification such as the change of a production method at short notice is simply unrealistic. This is clearly context-specific, but has a bearing across other industries and geographical boundaries.

Within the RBV, path dependencies are described as sources of costly imitation and rather more related to achievement of competitive advantage (Schroeder et al. 2002). It is necessary to understand that the main implications of dominant paths are likely to be reflected in restrictions of managerial decision making and capability building power, for the aforementioned reasons in earlier sections of this paper. It is important to re-emphasise that competitive advantage is unlikely to derive from the DC building exercise, as evidenced by the comments of managers in the research study who appear to suggest that, due to extensive consolidation in the steel sector, any routine modification is aimed at competitive survival in the short term. This is neatly illustrated by one interviewee who stated:

"The main driver of macro-environmental changes on the steel industry is the world consolidation process". [Director Business Planning] 
This is further corroborated by three interviewees, who give specific examples in relation to $\mathrm{M} \& \mathrm{~A}$ and a hint of the future make-up of the global steel industry:

"It's one of the most important tools, mergers and acquisitions, to respond to environmental changes.... we had two big acquisitions, in the USA and in Italy”.[Director Corporate University]

".....we will merge in some sort of "Russian Steel" or merge with somebody else or get acquired. Because the..... whole process will result in five, maybe ten global players.....to survive separately will be impossible”.[Director M\&A]

".......you probably have hundreds of steel companies in the world so just because of that the steel industry needs to consolidate in order to have enough leverage and influence on the prices of raw materials.....that's probably the only way to increase competitiveness for the steel industry relative to other industries". [Finance Director]

In effect, managerial knowledge to recognise and accept the above elements as major influencing factors in decision making allows business organizations to maintain more suitable resource materials which may then be applied to a variety of challenges or contextual problems. Consequently, dynamic capabilities in rapidly-changing environments may not in reality replace resources through renewal, a finding at variance with the general consensus emerging from the academic publications in this arena.

\section{Discussion}

In the earlier critique of the DC literature, an inherent paradoxical characteristic of dynamic capabilities is the focus on complete renewal of resource material and yet, dynamic capabilities cannot be built by imitation (Miller et al. 2002). Based on the empirical findings, there appear to be three main categories of blockages to managerial routine development for dynamic capability building in the Russian steel sector.

The first is that the total resource material in the industry will inevitably be subject to ongoing fluctuation due to natural dynamisms at the individual firm level. As a result, threshold standards of the industry (which are in turn highly dependent on, and ultimately moulded by, the combined resources within the industry) will be characterized by certain oscillations. Consequently, there is an inextricable and rather fine-grained connection between the sum of combined resources in the sector and the subsequent valid industry threshold capabilities. However, from the managerial perspective at corporate level, the latter are extremely difficult to identify due to both a natural time lag and ongoing changes in the macro environment which add a further dimension of complexity. 
The second and third categories of blockages are related to more practical implementation issues. Even if managers have successfully determined their own firm's position within the temporarily valid grid of total resource material in the industry and current "survival" capabilities, they may find it impossible to quickly react and adapt processes associated with the exercise of building capabilities. This may be due to existing path dependencies or financial constraints that particularly characterise the steel industry environment. Additionally, the issue of dynamic renewal may have additional negative connotations in practice. If problem-solving abilities are only called capabilities if firms are able to reproduce them, then reliability of organisational routines through repetition somewhat contradicts the basic notion of dynamic renewal. Figure 1 provides a diagrammatic illustration in the light of these findings.

\section{Figure 1: DC Building in the Steel Industry}

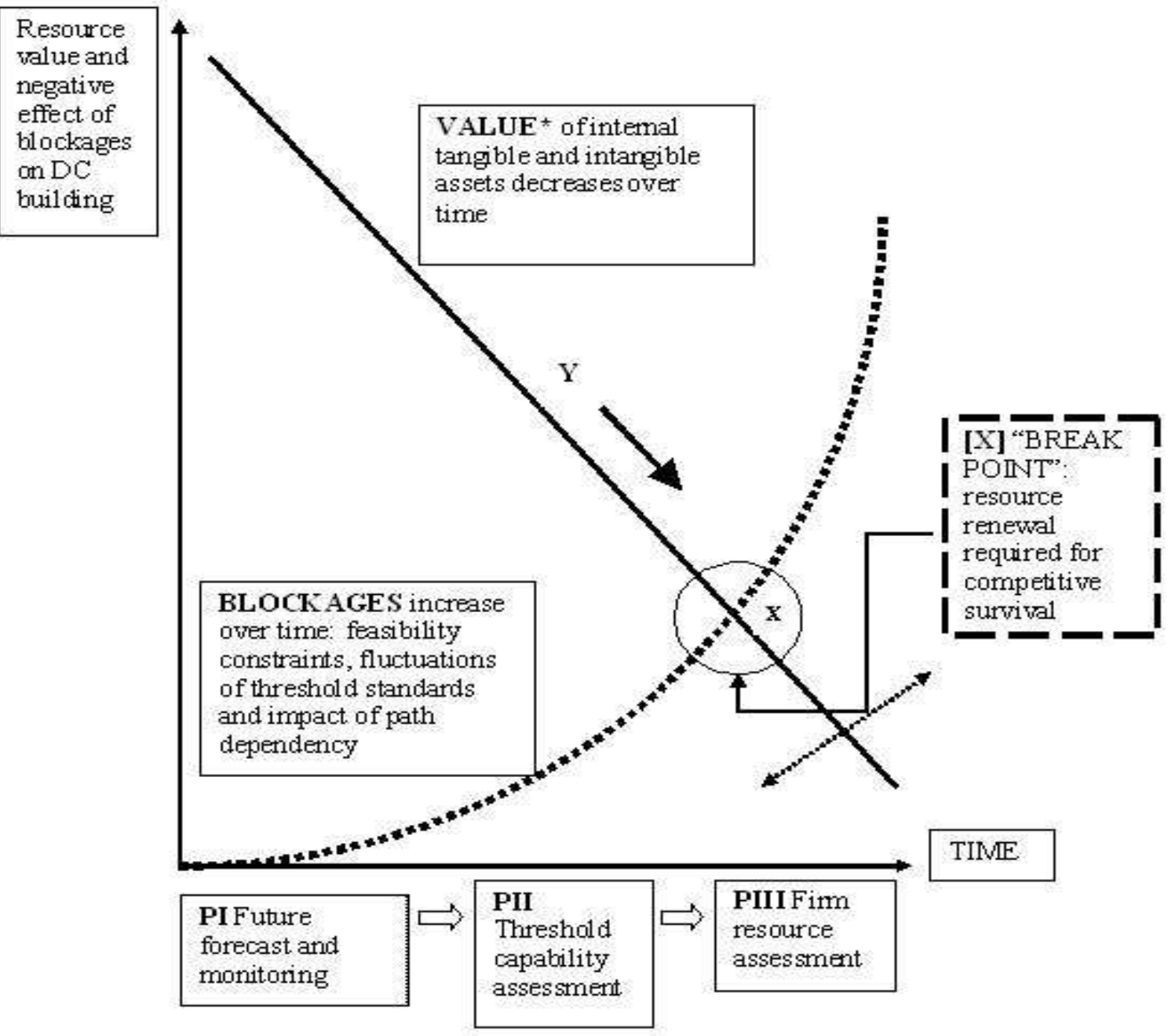

*Examples are physical depreciation of production facilities, demise of major production technologies and mental depreciation of contracts 
The figure illustrates that only three main phases (PI-PIII) of DC activities may be subject to complete and frequent renewal, i.e. the routines themselves which lie within managerial control. Phase I arises from the existing perspectives within the literature, whereas phases II and III emerge from the findings of this particular research and offer a tentative view of dynamic capabilities in action. More specifically, the phases represent the individual optimisation processes which are unique to firms and managerial abilities. They are part of the routine level and can be modified.

Conversely, resource raw material or existing resource stocks may not be subject to complete renewal. Any transformation on this level is likely to constitute more of a gradual process which is further constrained by both technological and financial factors as highlighted earlier. Hence the routines only facilitate full use of resource material from the managerial perspective.

In other words, two main elements of the overall exercise exist. Managers can create and modify routines. The outcome of this process is dependent on "current fit" with resource material. Because of continuous resource value "depreciation" in relation to threshold standards, any managerial routine patterns face substantial shifts to accommodate respective fluctuations. Hence a requirement for routine renewal is naturally given in order to maximise use of available resource material.

Although Figure 1 represents an attempt to 'visualise' the issues pertaining to dynamic capabilities based on previous researchers' work, as well the empirical data arising from the sector under consideration here, it is perhaps useful to consider the 'position' of the case organisation within this framework. The figure illustrates the existence of a hypothetical "break point" [X], where resource renewal is required for competitive survival. On reflection, the case organisation under investigation appears not to, in reality, have reached this point at the completion of the research study. On the evidence of senior managers, operational activities and steel production continued to run in a smooth, seemingly controlled manner. From a superficial point of view, the company was facing no imminent threats. Yet, as indicated on the diagram by "Y", symbolising the broad position of the company at the completion of the study, it was struggling with decreasing competitive strength, rapid intangible resource value depreciation and thus its trajectory appeared to be located on a downward slope, gradually slipping towards point "X". To use the analogy of rail tracks, the organisation was travelling on an idiosyncratic pathway, unable to quickly change direction or speed of travel. It is highly questionable whether any implementation of radical capability building based on resource renewal would be feasible given the specific industry constraints described above. Therefore, reaching the "break point" should be avoided at all costs.

Finally, the apparent paradox of dynamic capabilities, as discussed in detail by Schreyögg and Kliesch-Eberl (2007) and Ambrosini et al. (2009) for instance, 
may not be apparent after all. Commonalities across firms continue to exist. The findings of this research show that they may be found on a different level than the reviewed DC literature assumes. From the research undertaken, it appears that all industry players are likely to evaluate their resource raw material based on adherence to the same, only temporarily valid, threshold standards. For this reason, the renewal concept only affects the routine level within the wider DC framework. In addition, it demonstrates that too much focus on external monitoring may distract from the main stumbling blocks or blockages. However, it is important to note that the complexity of business reality may not always allow for sequential implementation of respective phases and their subsequent incorporation into managerial routines. Instead, awareness of their hierarchical status within the overall building exercise may represent the major benefit from the practitioners' perspective.

\section{Research Implications}

A number of issues and themes have surfaced in this paper, some corroborating existing ways of thinking in relation to DC, but others at variance with researchers in this field. This paper has sought to provide more tangible evidence as to the currency and validity of dynamic capabilities as a theory.

There are also practical implications. Managers may not realistically be able to rapidly modify processes, thus failing to build dynamic capabilities. This may be attributable to existing path dependencies or financial constraints, dependent on the micro environmental context - this certainly seems appropriate for the steel sector under investigation, where full resource renewal is unrealistic due to complexity of activities associated with possession, readiness and maintenance of resource material. These, combined with unpredictable fluctuation patterns of resource value, impact of external factors and time frames for future forecast result in ongoing "depreciation" of resource material. Under this premise, the following key implications for practitioners, illustrated in Table 1, might be emphasised.

Based on the discussion and arguments emerging from the research presented, the purpose of dynamic capabilities from a managerial perspective is not inevitably aimed at generation of competitive advantage, but more with the assistance of organisational survival within certain environments. In future, it seems likely that DC are likely to receive wider acceptance amongst senior managers, provided a greater clarity and focus exist in relation to their main objectives and purpose. Comments from managers arising in this research suggest that, thus far, and within the boundaries of the steel industry, this may still not sufficiently be the case. Further research is clearly needed to move this forward. 
Table 1: Managerial Implications for DC Building Processes in the Steel Industry

\section{PRACTICE IMPLICATIONS}

$\Rightarrow$ Managers should seek to minimise risk through constant evaluation of resource stocks in relation to industry standards, but be mindful that this is subject to ongoing fluctuations;

$\Rightarrow$ Managerial action should aim to embrace the practical obstacles of

$\circ$ potential rigidity of firm-specific unique historical conditions,

- robotic reaction to external signals by staff and,

- difficulties of implementing appropriate responses,

$\Rightarrow$ Managers can potentially emancipate the firm's future pathway from responses to

$\circ$ external signals and,

- continuation of existing problem-solving architecture and capability structures

as these act as barriers to rapid decision-making;

$\Rightarrow$ Determination of appropriate time spans for strategic forecasts is a critical senior management activity requiring continual review and re-validation.

In practical terms, however, only the accumulation of a knowledge base of industry applications of dynamic capabilities building will result in the development of more holistic frameworks. This, in turn, may permit comparison with insights from other research areas within strategy, and further illuminate on the evolutionary status of DC literature. Table 2 provides a summary of the academic ramifications arising from the findings of this research.

\section{Table 2: Theoretical Issues and Considerations}

\section{THEORY IMPLICATIONS}

As a theoretical construct, current thinking in relation to DC is presently focused on environmental surveillance and resource renewal. This research suggests that DC research should embrace an accumulation of industry-specific "guidelines" for managerial understanding of complex environments, addressing:

- fluctuating threshold value assessment;

- the monitoring and maintenance of suitable resource material as applied to situational contexts;

- path dependencies which may potentially block resource dynamisation;

- DC building activities based on the,

- establishment of adaptive tasks rather than routines,

o control of resource stocks and,

○ monitoring of flux in minimum capabilities required for organisational survival. 


\section{Conclusion}

The purpose of dynamic capabilities is not necessarily aimed at generation of competitive advantage, but assistance with organisational survival within certain contexts. Simultaneously, however, dynamic capabilities building processes alone may not necessarily provide sufficient momentum to achieve this. Understanding of complexities and development of appropriate responses incorporated into routines and processes may nevertheless help to reduce the uncertainties of recurring strategic challenges in individual instances. The study has also shown that, in light of adverse conditions as identified within the Russian steel industry, resource renewal and the subsequent need for DC building is further increased. In other words, a tentative positive association may exist between radical resource value depreciation and managers being forced into engagement with these complex activities. Engagement with the latter does not, however, guarantee their successful implementation.

To summarise, therefore, the main focus of attention in relation to the dynamic capabilities should not be categorisation of various dynamisation approaches, but an industry-based exploration of practical rigidities and managerial lock-ins within the overall DC building exercise. Dynamic capabilities represent firmspecific innovation search paths, but success will be subject to changes of threshold standards which, in turn, apply to all real players in the industry. Hence, the notion of competitive advantage in the usual sense of the RBV may represent a contradiction of the concept of DC. The availability of resource material in a given sector determines the "grade of survival potential" for individual firms. Thus, ongoing change, based on evolution in the external environment, somewhat diminishes the effect of monitoring and routine building over time. The central contradiction of dynamic capabilities, to commit to one path, but to conduct continuous routine modifications at the same time, may only be resolved via a move away from existing strategic architecture through identification of effective blockages, as illustrated in this research. Uniqueness from optimisation processes, decision-making speed through detachment from path dependencies, and complexity from ever-changing threshold definitions should guide managerial capability building activities.

It should be noted that one of the constraints of the research presented is the absence of data that would allow the measurement of performance implications. This is clearly a valid and potentially illuminating avenue of future research aimed at comparing DC building companies with other steel players, and this would further complement and enhance understanding of the complex area of DC presented in this paper. In essence, ongoing research will provide deeper comprehension of dynamic capabilities frameworks and industry-specific building exercises, as well as their limitations, serving as an important catalyst towards further maturity and acceptance of this strategy discipline. 


\section{References}

Ambrosini, V./Bowman, C./Collier, N. (2009): Dynamic capabilities: An exploration of how firms renew their resource base, in: British Journal of Management, 20 (Special Issue), 9-25.

Augier, M./Teece, D.J. (2007): Dynamic capabilities and multinational enterprise: Penrosean insights and omissions, in: Management International Review, 47, 2, 175-192.

Danneels, E. (2002): The dynamics of product innovation and firm competencies, in: Strategic Management Journal, 23, 12, 1095-1121.

Dosi, G./Nelson R.R./Winter, S.G. (2000): Introduction: The nature and dynamics of organisational capabilities, in: Dosi, G./Nelson, R.R./Winter, S.G. (eds): The nature and dynamics of organisational capabilities, New York: Oxford University Press, 122.

Dutta , S./Narasimhan, O./Rajiv, S. (2005): Conceptualizing and measuring capabilities: methodology and empirical application, in: Strategic Management Journal, 26, 3, 277 285.

Cunha, M.P. e/Cunha, V.J. da (2006): Towards a complexity theory of strategy, in: Management Decision, 44, 7, 839-850.

Eisenhardt, K.M./Martin, J.A. (2000): Dynamic capabilities: What are they? in: Strategic Management Journal, 21, 10-11, 1105-1121.

Ethiraj, S.K./Kale, P./Krishnan, M.S./Singh, J.V. (2005): Where do capabilities come from and how do they matter? A study in the software services industry, in: Strategic Management Journal, 26, 1, 25-45.

Filatotchev, I. (1996): How Russia became a market economy, in: World Economy, 19, 4, 478-480.

Green, S.D./Larsen, G.M./Kao, C.C. (2008): Competitive strategy revisited: Contested concepts and dynamic capabilities, in: Construction Management and Economics, 26, 1, 63-78.

Haas, M.R./Hansen, M.T. (2005): When using knowledge can hurt performance: The value of organisational capabilities in a management consulting company, in: Strategic Management Journal, 26, 1, 1-24.

Harreld, J.B./O'Reilly III, C.A./Tushman, M.L. (2007): Dynamic capabilities at IBM: Driving strategy into action, in: California Management Review, 49, 4, 21-43.

Helfat, C.E./Peteraf, M.A. (2003): The dynamic resource-based view: Capability lifecycles, in: Strategic Management Journal, 24, 10, 997-1010.

HSBC Global Research (ed.) (2008): Emerging markets now drive global steel demand, 17 April.

Irvine, H./Gaffikin, M. (2006): Getting in, getting on and getting out: Reflections on a qualitative research project, in: Accounting, Auditing \& Accountability Journal, 19, 1, 115-145

KPMG International (ed.) (2009): What's ahead for the metal's industry in 2009? April.

Lee, H./Kelley, D. (2008): Building dynamic capabilities for innovation: An exploratory study of key management practices, in: R\&D Management, 38, 2, 155-168. 
Lillis, B./Lane, R. (2007): Auditing the strategic role of operations, in: International Journal of Management Reviews, 9, 3, 191-210.

Miles, M.B./Huberman, A.M. (1994): An expanded sourcebook - qualitative data analysis, London: Sage.

Miller, D./Eisenstat, R./Foote, N. (2002): Strategy from the inside out: Building capabilitycreating organizations, in: California Management Review, 44, 3, 37-54.

Olearchyk, R. (2010): Ukraine sweats over Russian steel 'raiders', in: Financial Times, June 18.

Oliver, C./Holzinger, I. (2008): The effectiveness of strategic political management: A dynamic capabilities framework, in: Academy of Management Review, 33, 2, 496520 .

Pandza, K./Thorpe, A. (2009): Creative search and strategic sense-making: Missing dimensions in the concept of dynamic capabilities, in: British Journal of Management, 20, 1S, S118-S113.

Peng, M.W./Heath, P.S. (1996): The growth of the firm in planned economies in transition: institutions, organizations, and strategic choice, in: The Academy of Management Review, 21, 2, 492-528.

Pitelis, C./Verbeke, A. (2007): Edith Penrose and the future of the multinational enterprise: New research directions, in: Management International Review, 47, 2, 139-149.

Schreyögg, G./Kliesch-Eberl, M. (2007): How dynamic can organisational capabilities be? Towards a dual-process model of capability dynamisation, in: Strategic Management Journal, 28, 9, 913-933.

Schroeder, R.G./Bates, K.A./Junttila, M.A. (2002): A resource-based view of manufacturing strategy and the relationship to manufacturing performance, in: Strategic Management Journal, 23, 2, 105-118.

Spicer, A./McDermott, G.A./Kogut, B. (2000): Entrepreneurship and privatisation in Central Europe: The tenuous balance between destruction and creation, in: The Academy of Management Review, 25, 3, 630-649.

Stewart, C. (2007): PwC predicts strong M\&A activity in '08', in: The Moscow Times, Wednesday, October 17, 7.

Teece, D.J. (2007): Explicating dynamic capabilities: the nature and microfoundations of (sustainable) enterprise performance, in: Strategic Management Journal, 28, 3, 13191350 .

Teece, D.J./Pisano, G./Shuen, A. (1997): Dynamic capabilities and strategic management, in: Strategic Management Journal, 18 , 7, 509-533.

World Steel Association (2011): http://www.worldsteel.org, Accessed 10 May.

Wu, L-Y./Wang, C.J. (2007): Transforming resource to improve performance of technologybased firms: A Taiwanese empirical study, in: Journal of Engineering and Technology Management, 24, 3, 251-261.

Yung-Ching, H./Tsui-Hsu, T. (2006): The impact of dynamic capabilities with market orientation and resource-based approaches on NPD project performance, in: Journal of American Academy of Business, 8, 1, 215-229. 
Zollo, M./Winter, S.G. (1999): From organisational routines to dynamic capabilities, in: A Working Paper of the Reginald H. Jones Center, The Wharton School, University of Pennsylvania.

\section{Appendix One}

\section{Indicative interview schedule}

\section{Theme A Macro Environment}

How would you describe the general impact of continual macro environmental change on the steel industry? How can steel players anticipate future-related macro trends and changes? What exact procedures for strategic future forecast exist in your organisation? How would you describe the impact of macro-environmental changes and dynamics on senior managerial processes within your organisation?

\section{Theme B Resource Level}

What are the most important resource pools, both tangible and intangible, within the organisation? Could you please describe these resources and give some examples? How can existing resource pools be utilised in order to ensure competitive survival?

\section{Theme C Capability Level}

In increasingly dynamic environments, how can resource deployment processes contribute to organisational success? Specifically, what capabilities can you identify within your organisation? What exactly are the elements or procedures required to develop, apply and monitor processes associated with resource deployment in the Russian steel industry?

\section{Theme D Capability Building Processes}

What exact capability building or leveraging processes do you have in place in your organisation? As a senior manager, how do you measure success of these processes? 